\title{
MEDICAL ASPECTS OF RENAL CARCINOMA
}

\author{
Robert S. Pinals, M.D. \\ Postdoctoral Trainee, United States Public Health Service \\ STEPHEN M. KRANE, M.D. \\ Established Investigator of the Helen Hay Whitney Foundation \\ Department of Medicine, Harvard Medical School, and the Massachusetts General Hospital, Boston
}

ONLY a minority of patients with renal carcinoma present with the classical triad of flank pain, mass and hæmaturia. Various anomalous modes of presentation have been recognized. Quite commonly the clinical picture does not direct one's attention toward the kidney and patients are subjected to extensive diagnostic investigation before the nature of their disorder becomes clear. Thus, renal carcinoma must be considered in the differential diagnosis of a variety of maladies involving several organ systems. For this reason and also because of certain special features which may be associated with the tumour, such as polycythæmia, hypercalcæmia, amyloidosis, fever and the often peculiar behaviour of its metastases, many physicians other than urologists have been interested in renal carcinoma. In this paper we propose to review some aspects of this neoplasm which may be of interest to the internist and general physician.

\section{Natural History of the Disease}

Before embarking upon a discussion of the clinical vagaries of this neoplasm, it might be useful to review briefly some aspects of its development and behaviour. The old controversy as to whether the cellular progenitor of the tumour is renal or adrenal has been settled in recent years in favour of the former. However, the old term 'hypernephroma' is still in general use and will be used interchangeably with ' renal carcinoma'. Recent electron microscopic studies have illustrated certain close similarities between renal carcinoma cells and cells of normal convoluted tubules (Oberling, Rivière and Haguenau, I960). This would indicate that the tumour has its genesis somewhere in the renal cortex. Microscopic appearance is variable and includes papillary, tubular and solid arrangements of cells with either

This is Publication No. 315 of the Robert W. Lovett Memorial Group for the Study of Diseases Causing Deformities. clear or granular cytoplasm. With certain exceptions which will be mentioned later, these variations do not seem to influence the behaviour of the tumour in any significant way. Early growth is clinically silent, and it is impossible to determine the duration of this phase. However, one may deduce from indirect evidence, such as the slow subsequent course which the tumour often runs and the long history of hæmaturia or other symptoms with which patients sometimes present, that this silent phase may conceivably extend over a period of years. Graham (1947) reported an average delay of one year and eight months from the time of the first symptom until investigation of the urinary tract was undertaken. When the tumour is small, metastases are uncommon. Bell (1938) found metastases in only one case out of 39 wherein the tumour did not exceed $3 \mathrm{~cm}$. in diameter and in four of 22 cases with diameter between 3 and $5 \mathrm{~cm}$. When the diameter was over $5 \mathrm{~cm}$., metastases were found in 66 of 84 cases.

First symptoms occur with extension of the tumour toward the renal calyces and pelvis (hæmaturia), into the capsule and perinephric tissue (flank and abdominal pain) or renal venous network (symptomatic metastases). Hæmaturia, either gross or microscopic, is seen initially in roughly one-half the cases and develops later in others. However, failure to show positive urinary findings, even after other manifestations have been long present, is not uncommon and constitutes perhaps the most important diagnostic stumbling block. Melicow and Uson (1960) in a review of 183 cases which presented with 'non-urologic or atypical symptoms' (in a total group of 577 patients with renal cancer) found that $60 \%$ never had red blood cells in the urine. The kidney capsule usually remains intact until the tumour achieves a considerable size and becomes palpable in a variable proportion of cases (generally around one-third at initial presentation). Compression or 
infiltration of peri-renal structures may lead to dull flank, costovertebral or upper abdominal pain. Colicky pain is sometimes noted and is usually ascribed to passage of blood clots or bits of neoplastic tissue through the ureter. Local extension is not an important mode of spread in most cases. Occasionally atypical presenting symptoms are related to perinephric infiltration or hæmorrhage. Bloom (1959) reported a case of chronic hiccoughs disappearing after removal of a renal carcinoma adherent to the diaphragm. A recent case (Case Records of the M.G.H., I962) presented with severe abdominal pain suggesting perforation of a viscus, later found to be due to perinephric hæmorrhage from a renal cancer. A case with intraperitoneal hæmorrhage was reported by El-Toraei (1958).

Lymphatic spread is not a common early occurrence, although at post-mortem examination regional peri-aortic nodes are involved in about one-quarter of the cases. In examining 509 kidneys with hypernephroma, mostly nephrectomy specimens, McDonald and Priestley (1943) found invasion of perineural lymphatics in only one case. The most important mode of spread is by invasion of the renal venous system. This seems to occur quite regularly when the tumour reaches a certain size. Thrombosis or tumour growth may extend for a varying distance along the renal vein and sometimes propagates to the vena cava. Occasionally caval occlusion occurs, with œdema of the legs and evidence of collateral venous circulation. A propagating thrombus may become attached to the intima of the vein as it grows and may acquire its own blood supply from the vessel wall. Rarely such thrombi extend to the right atrium or dislodged fragments lead to pulmonary embolization. Infarction of the tumour, which is common, may be related to thrombosis of veins within the tumour. Renal vein or caval thrombosis may result in obstruction and retrograde flow of blood in the internal spermatic and ovarian veins, of which the left usually drains into the left renal vein and the right into the vena cava. Such a mechanism has been suggested to account for the fairly frequent occurrence of metastases in the testes and female genitalia as well as for the development of varicocele. The latter is variously reported in 0.6 to II. $4 \%$ of patients with renal carcinoma and occasionally is the first manifestation of the disease. Tumours causing varicocele tend to be large. Other retroperitoneal tumours and a variety of non-neoplastic conditions may be responsible for the development of varicocele later in life. However, its association with renal cancer is so frequent that such a development should be regarded as sufficient cause for pyelography or other appro- priate studies. This acute varicocele, similar tœ the benign varicocele which usually appears in youth, is almost always on the left side. Possibly because of its acute development, it is more ofter.

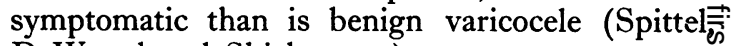
DeWeerd and Shick, 1959).

The occasional finding of ureteral and bladde metastases suggests that implantation of sheक. cancer cells in the distal urinary tract may be further mode of spread (Sargent, I960; Heslino Milner and Garlick, 1955). Cystic lesions occups in association with renal carcinoma with a fre $\overrightarrow{0}$ quency which may be greater than would beexpected by chance, although convincing statis. tical proof of this proposal has not been offeredo Gibson (1954), in discussing this subject, sug 3 gested that the mechanism for this might be combined tubular and vascular obstruction by the tumour resulting in impaired drainage of urine ands devitalization of tissue in an area of kidney adjacent to the tumour. He cited animal experiments which support this conclusion and em-o phasized that a tubular or vascular lesion alone would be insufficient to produce a cystic area. Ins other cases the cyst seems to arise within the tumour probably as a result of necrosis and $\overrightarrow{\mathbb{Q}}$ liquefaction, and in still others (Provet, Lisa afio Trinidad, 1956) small tumours have been foußd in the walls of solitary cysts. The practical i $\overrightarrow{0}$ portance of this association lies in the realizatign that cysts are the most important renal lesions which enter into the differential diagnosis of renap carcinoma. The demonstration of a cyst by various diagnostic measures does not eliminate then possibility of co-existing cancer. Cysts usually doo not cause hæmaturia, pain, weight loss and other $\stackrel{\circ}{\Rightarrow}$ signs and symptoms commonly found with neo-음 plasms, and if such are present exploration of the kidney is indicated.

Calcification within renal carcinomas has been reported in variable incidence, probably re- $\frac{0}{3}$ flecting the authors' interest in the subject. Cahill and Melicow (1938) reported the highest incidence, 14 out of 82 tumours showing calcification by X-ray. Surprisingly, they found the prognosis to be much worse in these cases. In ao recent review (Cannon, Zanon and Karras, I960) three categories were mentioned: (I) patchyo deposits; (2) diffuse calcification; (3) cystic calcification. Five cases of the latter wereos described. Thus, renal carcinoma must be in- N cluded in the differential diagnosis of nephro-N calcinosis along with tuberculosis, hydatid cysts, $\sigma$ disorders associated with hypercalcæmia and hypercalciuria, chronic pyelonephritis and others. The calcification should be unilateral unless the renal carcinoma is associated with hypercalcæmia or 0 two diseases are present. 


\section{Diagnosis}

Most delays in diagnosis can be attributed to failure to consider the possibility of renal neoplasm rather than to deficiencies in diagnostic techniques now in use. In cases presenting with urinary signs and symptoms, there is seldom any difficulty. Even among these, occasional patients with only isolated episodes of hæmaturia go without investigation until more persistent signs develop. The classical triad of hæmaturia, flank pain and mass occurs in only about $15 \%$ of cases. About a third of cases present without obvious evidence of renal disease. Various features of these cases will be discussed later. The mainstay of diagnosis is pyelography; recent confirmation of its effectiveness is found in a report by Evans, Halpern and Finby (196r), who found that in 100 patients with renal carcinoma only six had entirely normal pyelograms. However, in only 14 pyelograms was the radiologist entirely confident of the diagnosis of renal cancer. They discuss the types of pyelographic changes under four categories: (I) simple calyceal deformity; (2) polar enlargement of the kidney often with associated calyceal deformity; (3) diffuse enlargement of the kidney with calyceal elongation which may suggest polycystic disease; (4) invasion of the renal pelvis, simulating primary renal pelvis tumours. In a small proportion of cases, further investigative procedures may be called for. These include situations where pyelograms are negative, confusing or show minor changes, where differentiation between cyst and tumour is sought, and where insufficient suspicion exists to undertake exploration or the patient is a poor operative risk. Different techniques have been advocated, usually with favourable reported results, by persons familar with their use. In the hands of the inexperienced, information gained may be less useful and complications more frequent. According to some authors, arteriography is particularly valuable in distinguishing between cysts and tumours. Evans (r957) reported $95 \%$ accuracy with this technique. Good results have also been claimed for tomography (Van Velzer and Lanier, 1958; Evans, Halpern and Finby, 196I) in this differentiation, while Ney and Glanzman (1958) enjoyed similar success with presacral oxygen insufflation used in combination with pyelography. Abdominal venography has been used by Kaufman, Burke and Goodwin (1956) to define the extent of local spread and to investigate cases with possible recurrence after surgery. Cytologic studies of the urine have not proven to be as useful as in the diagnosis of lower genito-urinary tract malignancies. Evans, Halpern and Finby (r96r) report negative findings in all 55 cases tested. Others report false positives (Weyrauch and
Presti, 1956; Hazard, McCormack and Belovich, 1957).

\section{Anomalous Behaviour of Metastases}

In all series of hypernephromas, a large proportion of patients are found to present with signs or symptoms produced by metastatic lesions. In this category one might also include those who seek medical attention because of weight loss, weakness or debility since most of these will be found to have metastatic disease (though not all since occasionally these constitutional symptoms disappear, never to recur, after nephrectomy). About one-quarter to two-thirds of cases have evidence of metastatic disease when first admitted to the hospital, the wide range doubtlessly reflecting the thoroughness of investigation and duration of symptoms and signs before the initiation of diagnostic measures. The pattern of metastatic disease in renal carcinoma has peculiarities which distinguish it from other neoplasms and this subject will now be considered in some detail.

\section{Solitary Metastases and Metastases to Unusual and Unexpected Sites}

A voluminous literature attests to the fact that renal carcinoma may spread to extraordinary places and often may appear as a large, isolated metastatic lesion. This tendency may have some relationship to its early invasion of blood vessels and primary spread by the vascular route. Because of the distinctive histological picture of many renal cancers, biopsy of a metastasis often allows the pathologist to suggest the kidney as the site of origin. Pulmonary metastases are the most common. Large single lesions are easily confused with primary lung tumours. In several instances isolated involvement of the chest wall or mediastinal structures has been noted. A predilection for growth in the bronchial mucosa has provided several curious case reports. Creevy (1955) described a man with cough of three years duration who, on one occasion, coughed up a piece of tissue which, on histological examination, was diagnosed as carcinoma of undetermined origin. Chest $\mathrm{X}$-ray showed an infiltration at the right hilus, suggesting bronchogenic carcinoma. The patient later had hæmaturia, and pyelography revealed a kidney tumour. Re-examination of the sections of the coughed-up specimen showed it to have an appearance consistent with that of hypernephroma. A patient described by Caplan (1959) developed hæmoptysis from an endobronchial polypoid lesion which on biopsy was a clear-cell carcinoma similar to a tumor which had been removed by nephrectomy four years earlier. Similar cases have been described by Vinson and Martin (1932) 
and Berger and Sinkoff (1957). Bone metastases are next in frequency. The vertebral column is most commonly involved but there is hardly a bone in the body in which a metastatic lesion from hypernephroma has not been reported. Because metastases are often bulky, pulsatile, isolated, and may present before other clinical manifestations of tumour are apparent, confusion with primary bone tumours is common. Tumours of this sort are especially common in the humerus according to McClanahan and Bonann (1953), who reported three well-illustrated cases. Pulsating tumours have been reported in many bones, reflecting the vascularity of hypernephromas. Crile (I936) reviewed the literature on pulsating tumours of the sternum and found that the $\mathrm{I} 8$ reported cases were all metastatic tumours, nine from hypernephromas and nine from thyroid carcinomas. Cerebral metastases are fairly common and occasionally precede other evidences of disease (Creevy, 1955). A metastatic lesion in a meningioma was reported by Störtebecker (195I). Liver metastases are common at post-mortem examination but not often notable during life. However, a few cases have presented with a picture suggesting cirrhosis of the liver as in three cases of 92 reported by Creevy (1955). The opposite kidney is involved more often by metastases than one sees with other malignancies, but this is usually an autopsy finding without clinical importance. Hypernephroma is among the most common metastatic tumours involving the thyroid. In a review of the literature, Bruce and Michie (1954) found 22 cases. Since the microscopic appearance of hypernephroma sometimes resembles that of parathyroid tissues and also certain types of primary thyroid malignancy, much confusion may result in these cases. Involvement of the gastrointestinal tract which is usually late, has been discussed by Khilnani and Wolf (1960). There may be large intraluminal polypoid masses with ulceration and bleeding or obstruction. Involvement of the skin has been reviewed by Rosenthal and Lever (1957), who found 69 cases in the literature, in $20 \%$ of which skin lesions occurred before the diagnosis of renal carcinoma had been made. Vaginal and testicular metastases, for reasons which have been discussed previously, are more common with leftsided tumours. Martzloff and Manlove (1949) reviewed the subject of vaginal metastases and found several cases presenting initially with vaginal bleeding from vascular metastases. Of 23 cases only two had right-sided kidney tumours. Other unusual metastatic sites have included external auditory meatus, tongue, buccal mucosa, orbit, nasal septum, gingiva, atrioventricular node of the heart, pancreas, gall bladder, penis, epididymis, seminal vesicles and fingers. The frequent oc- currence of isolated metastases has led to surgic excision, sometimes by design and at other times without realization that the tumour was metastatie Cures are uncommon but there may be temporary benefit to the patient, and enough successfuit. excisions have been reported to inspire continue surgical efforts.

\section{Spontaneous Disappearance and Delayed $A p_{\widehat{D}}^{\frac{5}{5}}$ pearance of Metastases}

In a recent review of spontaneous regression o malignant disease, Everson and Cole (1959) found I 2 I cases acceptable to them in the world literature. Of these, I I were carcinomas of the kidney; onl $\overrightarrow{\mathrm{t}}$ choriocarcinomas and neuroblastomas were foung in greater number. Since this report several other cases have been added. Thirteen or I 4 cases of. spontaneous regression of pulmonary metastase $\omega_{0}^{\omega}$ have appeared in the literature. One questionable case (Hyman, I933) may have been an adrenal tumour. Regression of metastatic lesions otheor than pulmonary would appear to occur very rarely In ten cases pulmonary metastases were present at the time of nephrectomy (Ljünggren, Holm $\overrightarrow{\text { e }}$ Karth and Pompeius, 1959; Nicholls and Siddons $\mathbb{D}$ 1960; Arcomano, Barnett and Bottone, 1958 Mann, I948; Jenkins, 1959; Kessel, 1959 Hallahan, 1959; Samellas and Marks, I9 Böttiger, 1960a). In four cases pulmonary mea stases appeared after nephrectomy and subst. quently disappeared (Hyman, 1933; Beer, I93 Babbitt, Harwood and Peck, 1959; Bumpus, 1928). The pace of this regression varies con siderably. Most metastases vanished within matter of months after their appearance, but slowo regression has been noted as in the case of Jenkinso (1959). Most reported cases have remained free⿳亠丷厂 of further known metastases during the period of 3 follow-up, but in two cases (Arcomano, Barnett and Bottone, 1958; Ljünggren and others, 1959), brain metastases later developed. It might bé argued that radiological identification of metastases is insufficient evidence on which to draw con- $\frac{0}{3}$ clusions, since certain benign conditions may occasionally simulate their appearance. Only in one윽 case (Ljünggren and others, 1959) has biopsy of a pulmonary nodule been performed. However,궁 the radiological appearance of metastases has been quite typical in reports where $\mathrm{X}$-rays have been reproduced, and clinical and post-mortem study in $N_{\infty}^{N}$ some cases has shown no indication of other pulmonary disease which might be confused with metastases. A tendency toward spontaneous re- $\omega$ gression in the primary tumour has also been noted. In autopsy studies Bartley and Hultquist (1950) found several examples of small hypernephromas showing various degrees of regressive ${ }^{-}$ changes including fibrosis, hyalinization, calcifica- $-\frac{0}{3}$ 
tion. and changes in tumour cell morphology. Similar findings were reported later by Zak (1957). An adequate explanation for these phenomena is not available. The fact that regression often takes place after nephrectomy might suggest that some sort of ' trophic' factor produced by the primary tumour is necessary for the continued viability of metastases. Yet the observation that after nephrectomy several metastases have increased in size before regressing does not lend support to this possibility. Also, as mentioned above, some of these vanishing metastases did not appear until several weeks after nephrectomy. The problem will no doubt be elucidated when there is better understanding of host factors which restrain and modify growth of malignancies. This field is still in its infancy. Cases of regressing renal cancer might have great potential value in study of these factors.

Late appearance of metastases and very slow tempo of growth are other features which are more common in renal carcinoma than in most other cancers. Numerous case reports illustrate this phenomenon. Starr and Miller (1952) reported a solitary jejunal metastasis 20 years after nephrectomy. Kuehn and Davis (1959) described a local recurrence of renal carcinoma in the nephrectomy scar 12 years after surgery. Rosof and Rubin (I960) noted pulmonary and osseous metastases which appeared 20 years after nephrectomy. Bruce and MacLeod (1955) reported a case with survival for 24 years after discovery of an abdominal mass. Nephrectomy was not performed until I3 years after discovery of the tumour. Morton and Morton (1953) noted a case where a hypernephroma was removed 24 years before their report. A large femoral metastasis occurred 16 years later and the patient remained well for eight years following disarticulation of the femur. Humphreys and Foot (1960) described a patient who had survived for seven years after removal of roo cc. of carcinomatous tissue from within the vena cava.

\section{Fever}

The association of fever with renal carcinoma has been appreciated for at least 75 years. Credit for the first description is generally given to Stetter (1887). Subsequently, many authors have emphasized that renal carcinoma may present as 'fever of unknown origin'. The frequency with which fever occurs is difficult to determine from published data. Figures from i to $56 \%$ have been reported, but usually the criteria for fever in terms of degree and duration of temperature elevation have not been clearly outlined. Authors who have a particular interest in fever seem to report a higher incidence, possibly because they accept those ' febrile' cases with only small temperature elevations which others might ignore. About 20\% might be taken as an approximation of frequency. Fever may last from days to many months and may be of low degree or as high as $105^{\circ} \mathrm{F}$. The temperature chart may show any one of a large variety of patterns. According to Böttiger (1957) a constant temperature elevation of low degree is the most common finding ( 49 of 56 cases). The remaining seven cases had a spiking fever with return to the normal range, usually in the morning. Fever may be present in intermittent fashion with afebrile intervals of days to weeks. Although chills and sweats occur in rare cases in association' with high elevations, the patient is usually unaware of the presence of fever. In the absence of metastases disappearance of fever after nephrectomy is the rule. Thus in ten cases reported by Clarke and Goade (1956) all had remission of fever after nephrectomy except one in whom hepatic metastases were noted at the time of surgery. Fever may or may nor reappear when metastases later become evident. Occasionally, fever is not seen prior to nephrectomy but develops with the appearance of metastases. When antibiotics are given, there may seem to be a response, at least temporarily, in some cases. This can be accounted for by the natural tendency toward intermittency in the course of the pyrexia or perhaps sometimes by the presence of superimposed infection in the genitourinary tract or elsewhere. There may be a defervescence following the use of cortiscosteroids as shown in one case report (Greenberg, Ney and Feibush, 1952), but fever returned with discontinuation of the drug. It should be emphasized that although fever is common with renal carcinoma, only a small proportion of cases present with fever of extended duration as the sole significant clinical feature. In a recent review (Weinstein, Geraci and Greene, 196r) of 1,238 cases of renal carcinoma at the Mayo Clinic, I4I cases $(\mathrm{I} \mathrm{I} \%)$ had fever as a presenting symptom, $22(2 \%)$ had fever as the sole presenting symptom and only three cases qualified as genuine examples of ' fever of unknown origin' by virtue of having had fever over a prolonged period of time, unexplained after extensive study. One of these patients had daily elevations between $102-105^{\circ} \mathrm{F}$. for nine months. Cases of this sort are uncommon but leave such a lasting impression that many have found their way into the literature. Among the examples of extended pyrexia is the case reported by Nicholson (1927) of fever in a 38 -yearold woman lasting for 20 months. Pulmonary lesions near the hila appeared after i m months of fever and were thought to represent either primary lung tumour or Hodgkin's Disease. A diagnosis of renal carcinoma was made only at autopsy. 
The occurrence of fever is not related to sex or age according to most authors, although Böttiger (1960a) found some preponderance in females in a small series. Melicow and Uson (1960) noted no relationship to cell type. However, Murphy and Fishbein (I96r) reported that I9 of 46 granular cell carcinomas had fever greater than IOI ${ }^{\circ} \mathrm{F}$., whereas only four of 23 clear-cell carcinomas had fever of comparable degree. No difference in prognosis between febrile and afebrile patients was reported by Böttiger (1957), but McCormack and Amirana (I96I) found $22 \%$ five-year survival in patients who were febrile prior to surgery and $49 \%$ survival in those who were not. Apparently, the presence of fever cannot be well correlated with tumour size, the presence or absence of metastases, the degree of hæmorrhage and necrosis within the tumour or the incidence of superimposed urinary tract infection (Böttiger, I957). Many other malignancies may show fever with a paucity of other signs and symptoms, as a prominent feature of their clinical course (Browder, Huff and Petersdorf, r96r).

Among the possible mechanisms for fever in the absence of infection are: (I) Production of a pyrogenic substance by tumour cells. (2) Production of a pyrogen as a result of necrosis of tumour or adjacent normal tissue. Although this may play a role in some cases, the frequent association of fever with tumours devoid of hæmorrhagic or necrotic areas renders this theory unlikely as a general explanation for the phenomenon. (3) Infiltration of the tumour with granulocytes with release of the pyrogen which these cells are known to contain. A case of hepatoma in which this mechanism may have been operative is described by Browder, Huff and Petersdorf (196r). However, the absence of marked leukocytic infiltration in many feverproducing tumours would limit this possibility to a minority of cases. (4) Production of pyrogenic steroids such as etiocholanolone from modification of endogenous steroids by tumour cells or failure of steroid conjugation due to a derangement of liver function, either from metastases or from a specific metabolic impairment induced in some unknown manner by the tumour.

No experimental work directed at defining the responsible pyrogen has so far been reported.

\section{Polycythæmia}

The occurrence of polycythæmia with renal carcinoma was noted by Bliss in 1929 but was thought to be an incidental complication. A causal relationship was suggested later by Forssell (1946). It would appear that renal carcinoma accounts for from I to $5 \%$ of cases of polycythæmia. The incidence of polycythæmia in hypernephroma is of the same order. Damon, Holub, Melicovon and Uson (1958) found $2.6 \%$ in 350 patients $\frac{\%}{2}$ Ewert (1960) reported $2.1 \%$ in 140 patients an Berger and Sinkoff (1957) found $1.8 \%$ in 273 . patients. The characteristic features of this: polycythæmia, or more correctly $\epsilon$ rythræmia, whicks? serve to distinguish it from polycythæmia vera an $\Phi$ polycythæmia secondary to cardiopulmonar disease are: (I) absence of splenomegaly, leuko $\frac{}{5}$ cytosis and thrombocytosis; (2) normal arteriaß oxygen saturation; (3) remission after nephrectom in the absence of metastases; (4) normal leukocyte alkaline phosphatase. There are numerous ex ceptions to this classical picture. In a review of I 8 cases Lawrence and Donald (1959) found tha黑 six had splenomegaly, four had leukocytosis an three had thrombocytosis. It might be suggeste that some of these represent cases of simultaneoufs occurrence of polycythæmia vera and renal care cinoma. However, the issue is confused by the् knowledge that: (I) some of these atypical cases have had remission after nephrectomy, thus suggesting a causal relationship; (2) leukocytosiষ may result from the malignancy and bear no $\mathrm{re}_{\overrightarrow{\mathrm{C}}}$ lationship to the erythrocytosis; (3) as a result 06 wide dissemination of the cancer or treatmen directed against the polycythæmia, anæmia na develop later in the course of the disease. Thess factors make interpretation difficult in the atypical cases. The hæmatological remisstom which is noted in many cases after nepirectomy, with relapse in relation to the deo velopment of metastases, is well illustrated in the case reported by Omland (1959). Polycythæmi disappeared for three years after nephrectomy bu娄 returned coincident with pulmonary metastaseso Radiotherapy directed against these resulted in $\overrightarrow{5}$ second remission but thoracotomy later reveale $\$$ an unresectable tumour infilirating the medi? astinum. The patient did well for two years bu $\vec{P}$. then presented with dysphagia due to an ulcerating œsophageal tumour, histologically identical to his. original renal tumour, and recurrent polycythæmia Radiotherapy at this point produced a third remission of polycythæmia. The patient was alive at the time of the report, nine years after nephrectomy. Other benign and malignant conditions may occasionally produce an erythrocytosis wit characteristics identical to that seen with rena carcinoma. These include cerebellar hemangios blastoma, benign renal adenoma, hydronephrosiș polycystic kidney, uterine myoma and hepatoma Excessive elaboration of an erythrocyte stimulatingo factor (erythropoietin) by the tumour or adjacen kidney tissue has been proposed as the cause of the polycythemia. This has led to assays of tumou tissue and blood for erythropoietin by a variety of methods and with variable results. The problent 
is far from clear but at present this hypothesis would appear to be the most promising line of approach. The subject is covered in greater depth elsewhere in this issue.

The practical diagnostic application of this associarion between renal carcinoma and polycythemia is quite evident. Renal carcinoma should be considered in the differential diagnosis of polycythæmia and pyelography performed in those cases with: (I) suggestive evidence from history or physical examination; (2) abnormal findings on urinalysis; (3) elevated sedimentation rate (characteristically very slow in polycythæmia vera) without some other obvious explanation; (4) absence of leukocytosis, thrombocytosis and splenomegaly. Polycythæmia is often an early sign in cases of renal cancer in which it occurs and may provide a potentially life-saving diagnostic clue.

\section{Hypercalcæmia}

Carcinoma of the kidney is one of the more common tumours which metastasizes to bone. The skeletal lesions, characteristics of which have been discussed previously, are usually osteolytic in type. Although the exact incidence is difficult to ascertain, some of the patients with skeletal metastases have significant hypercalcæmia. Woodard (1953) reported that four out of 28 patients with carcinoma of the kidney, metastatic to bone, had serum calcium values greater than $12.0 \mathrm{mg}$. $/ 100 \mathrm{ml}$. In another study there were five patients with renal carcinoma out of 53 with both malignant disease and hypercalcæmia, an incidence of almost 10\% (Laird Myers, 1956). It is likely that additional patients with skeletal metastases would show hypercalciuria even in the absence of elevated serum calcium, as has been seen in other malignancies (Laszlo, Schulman, Sellin, Gottesman and Schilling, 1952).

In addition to the hypercalcæmia seen in patients with renal carcinoma who have extensive skeletal metastases, other patients have been described in whom the hypercalcæmia occurred in the absence of demonstrable bone lesions or in whom the metastases seemed inadequate to account for the elevation. Indeed, several patients have presented with symptoms referable only to the hypercalcæmia. Such symptoms included lethargy, constipation, weakness, polyuria and polydipsia, nausea and vomiting. The reported cases which are summarized in Table $I$ also include two additional patients from the authors' own experience. Of the II cases, all but two were males. All had significant hypercalcæmia as well as serum inorganic phosphorus values which were low or low normal in contrast to the elevation in serum phosphorus levels usually seen in patients with metastatic malignant disease. The blood chemical findings thus resemble those of primary hyperparathyroidism. Two of the I I cases had present or past evidence of renal stones. Serum alkaline phosphatase was, on at least one occasion, above 5.0 Bodansky units ( 15 K.A. units) in nine patients and above ro.o Bodansky units (30 K.A. units) in four. In six of these subjects removal of the renal carcinoma resulted in prompt fall in the serum calcium. In one of them (Case 7) the serum calcium increased to $10.6 \mathrm{mg} . / 100 \mathrm{ml}$. when metastases were observed. In another (Case II) the serum and urinary calcium remained normal despite extensive soft tissue metastases. One patient (Case IO) is of particular interest since he had a large, apparently solitary, metaistasis to the left lung. After removal of this tumour, weighing over $500 \mathrm{~g}$., the serum calcium fell to normal and remained normal until 12 days postoperatively when hypercalcæmia again recurred. This patient also had marked hypercalciuria, up to $470 \mathrm{mg} . / 24$ hours. Only one of these patients (Case 8) received an adreno-cortical steroid, which did not alter the serum calcium values.

The cause of the hypercalcæmia in these cases is not known. In those in whom the parathyroids were examined, either at operation or at autopsy, no abnormality was found, which makes it unlikely that the hypercalcæmic effect is mediated by the parathyroids. Note should be made, however, of the occurrence of renal cell carcinoma in a patient with primary hyperparathyroidism (Case Records of the M.G.H., I96 Ic). Attempts to demonstrate a calcium-mobilizing factor in the tumours have been unsuccessful (Albright and Reifenstein, 1946; Plimpton and Gellhorn, 1956; Case Records of the M.G.H., 196rb). It is likely, however, that these tumours are producing some substance (probably a polypeptide) that resembles the parathyroid hormone, since removal of the primary neoplasm has frequently resulted in return of the serum calcium and phosphorus to normal. From the available data, it is difficult to determine whether extensive tumour necrosis is necessary for the hypercalcæmic effect. The possibility that the hypercalcæmia is due to abnormal binding of calcium in the serum has been discussed (Plimpton and Gellhorn, 1956; Huth, $196 \mathrm{I}$ ) but is unlikely in view of the hypercalciuria sometimes observed, as well as the fact that symptoms referable to the hypercalcæmia per se have been described and have remitted after removal of the tumour. It is of interest that a transplantable papilloma in rabbits had produced hypercalcæmia, hypophosphatæmia and bone resorption unassociated with skeletal metastases (Wilson, Merric, and Woodward, I96r). Similar findings in humans have also been observed with 
TABLE I

Hypercalcemia and Renal Carcinoma

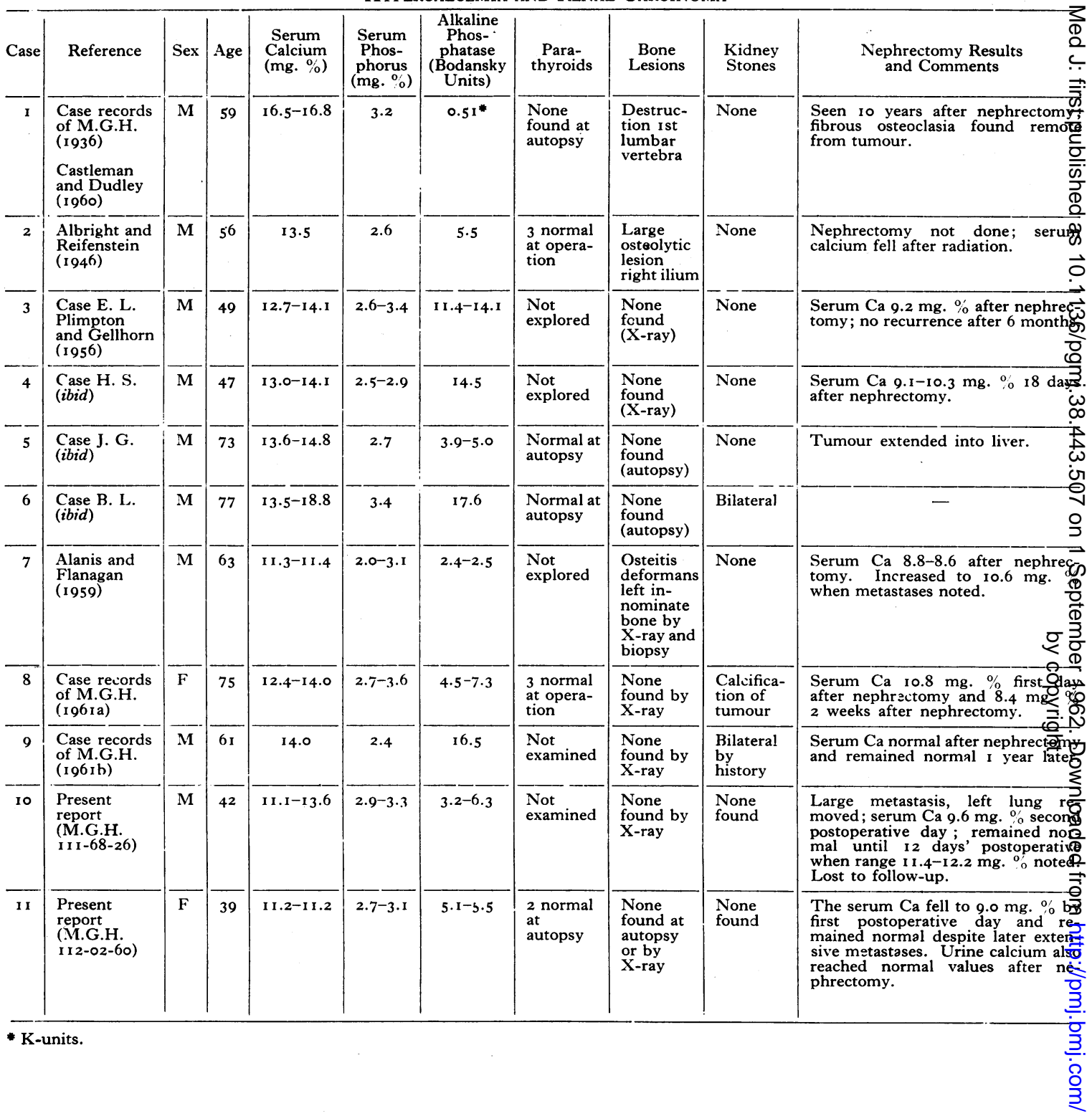

malignant tumours other than those from the kidney (Connor, Thomas and Howard, 1956; Plimpton and Gellhorn, 1956; Huth, 1961).

\section{Amyloidosis}

A small proportion of cases of secondary amyloidosis is related to malignant disease (Dixon, 1934). If myeloma is excluded, renal carcinoma and Hodgkin's disease appear to be by far the most common malignancies associated with amyloidosis. Richmond, Sherman, Diamond and Craver (1962) found amyloid deposits in $3 \%$ of cases of
Hodgkin's disease and none in other lymphomas Over 30 cases have been reported with hyper nephromas. Hyman and Leiter (1946) found a. incidence of $1.3 \%$ in 300 cases. Berger and Sinkoff (1957) found $3.0 \%$ in 273 cases. The subject has been reviewed in detail by Pigeaud (1956). The usual clinical picture is one of rapid deterioration and uræmia. Hepatomegaly an splenomegaly may occur but are not invariable Albuminuria is greater than in the usual case of hypernephroma, although a few cases have hait very minimal or no albuminuria. Only a minorit床 
of patients have frank nephrotic syndrome. The Congo red test has been abnormal in several cases. Some patients have had anæmia and fever but it is difficult to judge whether these occur more often than among hypernephromas in general. Diagnosis is usually made on autopsy or nephrectomy. The responsible tumour may be of any size and may or may not have metastases.

Some authors have remark ¿d upon the presence of necrosis and hæmorrhage within the tumour but apparently this is not always present. The distribution of amyloid deposits does not seem to differ from that seen in secondary amyloidosis from other causes. Liver, kidney, spleen and adrenals are most often involved (Ask-Upmark, 1940). A few cases have had deposition in the gastrointestinal tract and less commonly steatorrhea occurs (Bogaert, de Loecker and Tverdy, 1960). Amyloid material may also be found within the tumour. Although reversibility of secondary amyloidosis is possible when the causative lesion is removed, sufficient information is not available from cases with renal carcinoma to determine whether this has ever taken place. Most patients have deteriorated rapidly after nephrectomy. A patient reported by Bogaert, deLoecker and Tverdy (1960) was still living two years after nephrectomy and continued to have azotæmia and gross albuminuria. However, less Congo red was retained in the tissues than on initial testing.

In recent years amyloidosis has been the subject of numerous clinical and experimental studies (Calkins, Cohen and Larsen, r960; Kennedy, 1962). The role of malignancies in the production of amyloidosis is obscure as is the explanation for its relatively high incidence with renal carcinoma. Mechanisms which might be considered are: (I) release of a circulating precursor of amyloid, possibly a glycoprotein, by tumour cells; (2) stimulation of production of such a material elsewhere, perhaps in the lymph nodes or liver, either by something secreted by the tumour or by breakdown products; (3) modification of normal blood or tissue components by the neoplastic process. Any theory must account for the fact that amyloidosis is quite rare among the total population of tumours. Possibly the development of amyloidosis is a function of time. Myeloma and lymphoma may run chronic courses and, as we have seen, hypernephroma may also. However, one cannot conclude from available information that hypernephromas which result in amyloidosis have been present longer than those which do not. Such information will probably not be forthcoming since it is impossible to know how long the renal tumour has been present before it becomes clinically manifest.

\section{Miscellaneous Manifestations} Hypertension

Some authors have commented upon a relationship between hypertension and hypernephroma. Partial obstruction of the renal artery has been suggested as a possible explanation. However, McDonald and Priestley (1943) found no evidence of neoplastic involvement of the artery in any of the 509 kidneys they examined. Morlock and Horton (1936) noted no unusual incidence of hypertension in their series and no significant change in blood pressure after nephrectomy. Melicow and Uson (1960) found eight cases with hypertension among 183 patients. Only one had return to normal blood pressure after nephrectomy. Polymyositis or Dermatomyositis

This has been observed with a variety of neoplasms. We are aware of only two cases which have been reported with renal carcinoma. One patient (Alanis and Flanagan, 1959) presented with profound, progressive weakness, muscle atrophy and hypercalcæmia. Muscle. biopsy showed degeneration of muscle fibres and infiltration with chronic inflammatory cells. After removal of a renal carcinoma, his serum calcium returned to normal, weakness diminished and a second muscle biopsy showed improvement.

In another case (Cottel, 1952), which seemed typical of dermatomyositis except for the absence of a rash, a small renal carcinoma was discovered at autopsy.

\section{Leukemoid Reaction}

Marked elevations of leukocyte counts are seen rarely with a variety of neoplasms. Renal carcinoma is no exception but there is no reason to believe that the incidence is higher than with other cancers. The general subject is reviewed by Hensler (1953). He reported a hypernephroma with a white blood count of $67,000 / \mathrm{cu}$. $\mathrm{mm}$. There were widespread metastases and considerable necrosis. Another reported case (Case Records of the M.G.H., I957) also had marked tumour necrosis. This excessive stimulation of myelopoiesis is usually attributed to tumour necrosis, but the rarity of leukemoid reactions contrasted with the common occurrence of necrosis suggests that additional mechanisms may be operating.

\section{Salt-losing Syndrome}

A curious case was reported by Lassen and Sagild (1960) wherein the patient presented with dehydration, weakness, hyponatræmia, azotæmia and acidosis. Large urinary losses of salt and water were demonstrated. Differential renal function studies showed that $90 \%$ of the sodium excretion was from one kidney. This kidney was later 
found to be almost entirely replaced by a renal carcinoma. After nephrectomy the patient was able to conserve sodium normally. Apparently, for some obscure reason, the tumour resulted in a leakage of plasma-like fluid into the urine.

\section{Arteriovenous Fistula.}

Hypernephromas tend to be rather vascular tumours. Mention has already been made of pulsating metastases. Some of these may result in shunting of blood sufficient to cause hæmodynamic changes (Caplan, Sparkes, Lemay and Mahoney, 1961). Arteriovenous shunting may also be seen in the primary tumour. One patient (Bacon, 1958) presented with a continuous murmur in the left midaxillary line. Scheifley Daugherty, Greene and Priestley (1959) reviewed the subject of renal arteriovenous fistulæ and found 15 cases of which three were associated with hypernephroma.

\section{Abnormalities of Liver Function}

A recent abstract (Stauffer, I96I) reported five cases of hypernephroma with hepatosplenomegaly and abnormal liver function tests. In one case an alkaline phosphatase of 57 K.A. units returned to normal after nephrectomy. Similar improvement in liver function tests after nephrectomy was found in another case (Case Records of the M.G.H., r96ra). Interpretation of these findings must await further data.

\section{Sedimentation Rate and Serum Protein Abnormalities}

This has been emphasized by many authors. Melicow and Uson (1960) found that 73 of 95 patients had sedimentation rates (Westergren) over 35. Böttiger (1960a) found $24 \%$ normal, $50 \%$ elevated but below 30 , and $26 \%$ over 30 . The test may be of some diagnostic value if elevated, especially in distinguishing between renal carcinoma and cyst. Polycythæmia with renal carcinoma may be associated with a higher sedimentation rate than polycythæmia vera. However, as is usually the case, the sedimentation rate gives nonspecific information which must be bolstered by more definitive data before one makes a decision for or against exploratory surgery.

Serum protein studies have been reported by Böttiger (1960b) who found a significant elevation of serum glycoproteins, alpha-2 globulins and haptoglobin. These changes returned toward normal with removal of the tumour. However, there is no definite evidence that these abnormalities differ basically from those which may be seen with many types of malignancy (Shetlar, 196r). Some interesting histochemical studies by Böttiger ( $1960 \mathrm{~b}$ ) revealed a correlation between the abnormal serum proteins mentioned above and the incidence of an unidentified PAS-positive material 3 in the cytoplasm of renal carcinoma cells.

\section{Anamia}

A normochromic, normocytic anæmia may be found in hypernephroma as in many othero malignancies. Widely varying percentages of incidence have been reported, often without $\frac{\bar{\rho}}{\bar{\sigma}}$ adequate definition of levels acceptable as 'anæmic'. As expected, anæmia is generally more severe and prevalent in cases with widespread metastases. Occasionally anæmia and constitutional symptoms, $\stackrel{-}{-}$ such as weight loss, weakness and fatigue, are the $\vec{\omega}$ sole presenting complaints. Such cases offer great diagnostic difficulty until some further development calls attention to the kidney. Of course 3 . this situation is duplicated by many other visceral ${ }_{\infty}^{\dot{\infty}}$ malignancies.

Lindau-Von Hippel Disease
A recent report (Kaplan, Sayre and Greene, 1961) emphasizes an old observation of the음 association between hæmangiomata of the retina and cerebellum with multiple renal carcinomas. $\infty$ The authors point out that when patients with renal carcinoma develop signs suggestive $\mathrm{gf}^{\mathbb{D}}$ cerebellar tumour, this syndrome should be considered in addition to metastatic malignanog.

\section{Cushing's Syndrome}

An interesting association between maligna tumours and Cushing's syndrome has been described. However, until 196r in none of the reported cases was renal carcinoma present. Riggs and Sprague (196r) observed three patients with $\stackrel{\circ}{\varnothing}$ hypernephroma among 13 patients with malignant $\underset{\Rightarrow}{\Rightarrow}$ tumours and Cushing's syndrome. One of these patients was a 47-year-old female who had typical signs and laboratory findings of adrenocorticalo hyperfunction in addition to a small hypernephroma of the right kidney. Removal of the 3 renal carcinoma and simultaneous subtotal resection of hyperplastic adrenals resulted in remission of the Cushing's disease. The possibilityo that the tumour was producing an ACTH-like substance was postulated but not proven in thiso case.

\section{Concluding Remarks}

In this review we have made no attempt to discuss treatment of renal carcinoma. However, N it should be emphasized that in many cases theN previously discussed systemic manifestations such ${ }_{\sigma}^{\omega}$ as fever, polycythæmia, hypercalcæmia, myopathy and perhaps amyloidosis may regress after removale of the tumour. Thus, these manifestations dow not indicate inoperability in this disease where surgery is the treatment of choice. 


\section{REFERENCES}

Alanis, B. F., and Flanagan, J. F. (1959): Myopathy and Hypercalcemia Occurring with Carcinoma of the Kidney, F. Amer. med. Ass., 171, 2076.

Albright, F., and Reifenstein, E. C., Jr. (1946): ' The Parathyroid Glands and Metabolic Bone Disease '. Baltimore: Williams and Wilkins.

Arcomano, J. P., Barnett, J. C., and Bottone, J. J. (1958): Spontaneous Disappearance of Pulmonary Metastases Following Nephrectomy for Hypernephroma, Amer. F. Surg., 96, 703.

Ask-Upmark, E. (1940): On Amyloidosis Induced by Tumours of the Kidney, Acta med. scand., 104, 512.

Babbitt, R. M., Harwood, I. R., and PECK, F. M. (1959): Behavior of Certain Metastatic Diseases Arising in the Urinary Tract, $\mathcal{F}$. Urol., 81, 629.

Bacon, A. P. C. (1958): Hypernephroma Presenting as a Continuous Murmur in the Chest, Brit. med. Y., ii, 729.

BARTLEy, O., and Hultquist, G. T. (1950): Spontaneous Regression of Hypernephromas, Acta path. microbiol. scand., 27,448 .

BeER, G. (1937): Some Aspects of Malignant Tumors of the Kidney, Surg. Gynec. Obstet., 65, 433.

BeLL, E. T. (1938): A Classification of Renal Tumors with Observations on the Frequency of Various Types, $\mathcal{F}$. Urol., 39, 238.

Berger, L., and Sinkoff, M. W. (1957): Systemic Manifestations of Hypernephroma, Amer. F. Med., 22, 791.

BLISs, T. L. (1929): Basal Metabolism in Polycythemia Vera, Ann. intern. Med., 2, 1155.

BцоOM, V. R. (1959): Hypernephroma Presenting with Intractable Hiccup, Lancet, i, 915.

BOGAERT, R., DELOECKER, W., and TVERDY, G. (1960): Amyloidose secondaire au carcinome renal: Etude clinique de trois Cas, Acta clin. belg., I5, 81.

BötTiger, L. E. (1957): Fever of Unknown Origin: IV. Fever in Carcinoma of the Kidney, Acta med. scand., 156, 477. (1960a): Studies in Renal Carcinoma: I. Clinical and Pathologic Anatomical Aspects, Ibid., 167, 443.

- (1960b): Studies in Renal Carcinoma: II. Biochemical Investigations, Ibid., 167, 455.

Browder, A. A., Huff, J. W., and Petersdorf, R. G. (1961): The Significance of Fever in Neoplastic Disease, Ann. intern. Med., 55, 932 .

BrucE, G. G., and MiCHIE, W. (1954): Metastatic Hypernephroma of the Thyroid Gland, Brit. F. Surg., 42, 257.

BRUCE, J., and MACLEOD, J. G. (1955): Long Survival in Renal Carcinoma, Brit. med. $\mathcal{Y}$., i, 1323.

Bumpus, H. C. (1928): The Apparent Disappearance of Pulmonary Metastasis in a Case of Hypernephroma Following Nephrectomy, $\boldsymbol{F}$. Urol., 20, 185.

Cahill, G. F., and Melicow, M. M. (1938): Calcification of Renal Tumours and its Relation to Prognosis, Ibid.; 39, 276.

Calkins, E., Cohen, A. S., and Larsen, B. (1960): Amyloidosis: Preliminary Clinical, Chemical and Experimental Observations, Ann. N.Y. Acad. Sci., 86, 1033.

Cannon, A. H., Zanon, B., and KarRas, B. G. (I960): Cystic Calcification in the Kidney-Its Occurrence in Malignant Renal Tumors, Amer. F. Roentgenol., 84, 837.

Caplan, H. (1959): Solitary Endobronchial Metastasis from Carcinoma of Kidney, Brit. F. Surg., 46, 624.

Caplan, H. I., SPARKES, R. S., LemaY, M. J., and MAhONEY, D. (196r): Arteriovenous Shunt Produced by Metastatic Hypernephroma, F. Amer. med. Ass., 177, 788.

Case Records of the M.G.H. (1936): New Engl. Y. Med., 214, 425.

Case Records of the M.G.H. (1957): Ibid., 257, 1039.

Case Records of the M.G.H. (1961a): Ibid., 264, 242.

Case Records of the M.G.H. (196rb): Ibid., 265, 953 .

Case Records of the M.G.H. (I96rc): Ibid., 265, 957.

Case Records of the M.G.H. (1962): Ibid., 266, 563 .

Castleman, B., and DudLEy, H. R. (I960): 'Clinicopathological Conferences of the Massachusetts General Hospital '. Boston: Little, Brown.

Clarke, B. G., and Goade, W. J., Jr. (1956): Fever and Anemia in Renal Cancer, New Engl. F. Med., 254, 107.

Connor, T. B., Thomas, W. C., Jr., and Howard, J. E. (1956): The Etiology of Hypercalcemia Associated with Lung Carcinoma, f. clin. Invest., 35, 697.

CotTel, C. E. (1952): Dermatomyositis and Malignant Neoplasm, Amer. F. med. Sci., 224, r6o.

Creevy, C. D. (1955): Confusing Clinical Manifestations of Malignant Renal Neoplasms, Arch. intern. Med., 55, 895.

CRILE, G. (1936): Pulsating Tumors of the Sternum, Ann. Surg., ro3, 199.

Damon, A., Holub, D. A., Melicow, M. M., and Uson, A. C. (I958): Polycythemia and Renal Carcinoma, Amer. F. Med., 25, 182 .

Dixon, H. M. (1934): Renal Amyloidosis in Relation to Renal Insufficiency, Amer. F. med. Sci., 187, 401.

EL-TORAEI, I. (1958): Emergency Nephrectomy for Hypernephroma Causing Massive Intraperitoneal Hemorrhage, F. Urol., 80, 297.

Evans, A. T. (1957): Renal Cancer: Translumbar Arteriography for its Recognition, Radiology, 69, 657.

Evans, J. A., HalPern, M., and Finby, N. (1961): Diagnosis of Kidney Cancer, Y. Amer. med. Ass., I75, 201.

Everson, T. C., and ColE; W. H. (1959): Spontaneous Regression of Malignant Disease, Ibid., 169, 1758.

EwERT, E. E. (1960): Renal Cell Carcinoma and Polycythemia, Surg. Clin. N. Amer., 40, 767.

Forssell, J. (1946): Polycythemia in a Patient with Hypernephroma, Nord. med., 30, 1415.

Gibson, T. E. (1954): Interrelationship of Renal Cysts and Tumors: Report of Three Cases, f. Urol., 7r, 241.

Graham, A. P. (1947): Malignancy of the Kidney: Survey of 195 Cases, Ibid., 58, ro.

Greenberg, D., NEY, C., and Feibush, J. S. (1952): Obscure Fever Caused by Carcinoma of the Kidney, Arch. intern. Med., 90, 395 .

Hallahan, J. D. (1959): Spontaneous Remission of Metastatic Renal Cell Adenocarcinoma: A Case Report, F. Urol., $81,522$.

HazARD, J. B., McCormack, L. J., and Belovich, D. (1957): Exfoliative Cytology of the Urine with Special Reference to Neoplasms of the Urinary Tract: Preliminary Report, Ibid., 78, I82.

Hensler, L. (1953): Hohe Leukocytose durch Karzinom, Schweiz. med. Wschr., 83, 1032. 
Heslin, J. E., Milner, W. A., and GaRLick, W. B. (1955): Lower Urinary Tract Implants or Metastases from Cleaß̃ Cell Carcinoma of the Kidney, $\boldsymbol{F}$. Urol., 73, 39.

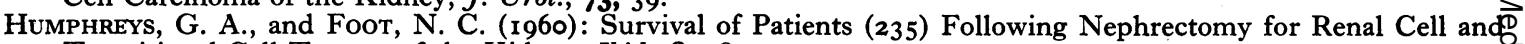
Transitional Cell Tumors of the Kidney, Ibid., 83, 81 5 .

Huth, E. J. (196I): Hypercalcemia-Doubled Causes and a Dilemma, Ann. intern. Med., 54, 1026.

Hyman, A. (1933): A Clinical Study of Malignant Tumors of the Kidney, Surg. Clin. N. Amer., r3, 347.

Jenkins, G. D. (1959): Regression of Pulmonary Metastases Following Nephrectomy for Hypernephroma: Eight-yeace Follow-up, Ibid., 82, 37.

Kaplan, C., SAYre, G. P., and Greene, L. F. (1961): Bilateral Nephrogenic Carcinomas in Lindau-Von Hippel Disease $\frac{\overline{\bar{p}}}{\overline{5}}$ Ibid., 86, 36 .

Kaufman, J. J., Burke, D. E., and Goodwin, W. E. (1956): Abdominal Venography in Urological Diagnosis, Ibid.? 75, 160.

KENNEDy, J. S. (1962): Sulphur-35 in Experimental Amyloidosis, f. Path. Bact., 83, 165.

KESSEL, L. (1959): Spontaneous Disappearance of Bilateral Pulmonary Metastases, $\mathscr{\Im}$. Amer. med. Ass., 169, 1737.

KhILNANI, M. J., and Wolf, B. (1960): Late Involvement of the Alimentary Tract by Carcinoma of the Kidney Amer. F. dig. Dis., 5, 529.

Kuern, C. A., and Davis, P. (1959): Carcinoma of the Renal Parenchyma: Long-Term Survival; Report of a Cas and Five-year Review of Literature, $\mathcal{F}$. Urol., 81, 519.

Laird Myers, W. P. (1956): Hypercalcæmia in Neoplastic Disease, Cancer, 9, 1135.

LASSEN, U. V., and SAGILD, U. (1960): Salt-losing Syndrome Due to Unilateral Renal Disease (Hypernephroma) Acta med. scand., 168, 65 .

laszlo, D., Schulman, C. A., Sellin, J., Gottesman, E. D., and Schilling, A. (1952): Mineral and Protein Meta $\stackrel{P}{+}$ bolism in Osteolytic Metastases, $\mathcal{Y}$. Amer. med. Ass., 148, 1027.

Lawrence, J. H., and Donald, W. G. (1959): Polycythemia and Hydronephrosis or Renal Tumors, Ann. intern' Med., 50, 959 .

Ljünggren, E., Holm, S., Karth, B., and Pompeius, R. (1959): Some Aspects of Renal Tumors with Special Refero ence to Spontaneous Regression, $\mathfrak{F}$. Urol., 82, 553.

McClanahan, C. W., and Bonann, L. J. (1953): Signal Skeletal Metastases from Renal Carcinoma, Amer. F. Roent $\overrightarrow{-}$ genol., 70, 387.

McCormaCK, J. L., and Amirana, M. (196r): Fever as a Symptom in Renal Carcinoma, f. Urol., 86, 518.

McDonald, J. R., and PRIESTLEY, J. T. (1943): Malignant Tumors of the Kidney, Surg. Gynec. Obstet., 77, 295.

ManN, L. T. (1948): Spontaneous Disappearance of Pulmonary Metastases After Nephrectomy for Hypernephronea F. Urol., 59,564 .

Martzloff, K. H., and Manlove, C. H. (1949): Vaginal and Ovarian Metastases From Hypernephroma, Surg. Gynge Obstet., 88, 145 .

Melicow, M. M., and Uson, A. C. (1960): Non-urologic Symptoms in Patients with Renal Cancer, F. Amer. me ब융 Ass., $172,146$.

Morlock, C. G., and Horton, B. T. (1936): Variations in Systolic Blood Pressure in Renal Tumor: A Study of $\underset{49}{5}$ Cases, Amer. F. med. Sci., rgr, 647.

Morton, J. J., and Morton, J. H. (I953): Cancer as a Chronic Disease, Ann. Surg., r37, 683.

Murphy, G. P., and Fishbern, R. H. (196r): Clinical Manifestations and Cytology of Hypernephromas, f. Urol. $85,483$.

Ney, C., and Glanzman, S. (1958): Use of Pre-sacral Oxygen Insufflation in Renal Tumors and Cysts Undiagnosed by Routine Procedures, Geriatrics, 13, 733 .

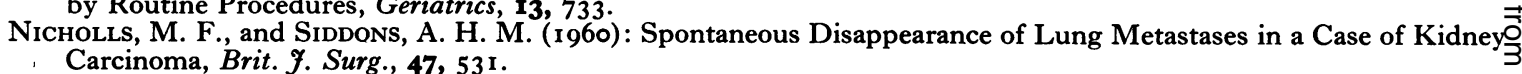

Nicholson, D. (1927): Fever with Renal Carcinoma, Arch. Path., 3, 393.

Oberiing, C., Riviere, M., and Haguenau, F. (1960): Ultrastructure of the Clear Cells in Renal Carcinomas and itșo Importance for the Demonstration of Their Renal Origin, Nature, 186, 402.

Omland, G. (1959): Polycythæmia in Renal Carcinoma, Acta med. scand., 164, 451 .

Pigeaud, M. (1956): Amylose et Cancer du Rein, Thèse de Paris.

Plimpton, C. H., and Gellhorn, A. (1956): Hypercalcemia in Malignant Diseases Without Evidence of Bone Destruction, Amer. $\mathcal{F}$. Med., 21, 750 .

Provet, H., Lisa, J. R., and Trinidad, S. (1956): Tubular Carcinoma of the Kidney Within a Solitary Cyst, F. Urol.. $75,627$.

Richmond, J., Sherman, R. S., Diamond, H. D., and Craver, L. F. (1962): Renal Lesions Associated with Malignant Lymphomas, Amer. F. Med., 32, 184.

Riggs, B. L., and SPRAGUe, R. G. (196I): Association of Cushing's Syndrome and Neoplastic Disease, Arch. intern. $\rightarrow$ Med., ro8, 85 .

Rosenthal, A. L., and Lever, W. F. (1957): Involvement of the Skin in Renal Carcinoma, Arch. Derm., 76, 96.

Rosof, B. M., and Rubin, R. (1960): Metastasis from Hypernephroma Twenty Years After Nephrectomy, F. Amer. $\mathcal{O}$ med. Ass., 173, 896 . mamellas, W., and Marks, A. R. (I96I): Apparent Spontaneous Regression of Pulmonary Metastases Following
Nephrectomy for Adenocarcinoma of the Kidney, $\boldsymbol{\Im}$. Urol., 85, 494.

SARgent, J. W. (1960): Ureteral Metastasis from Renal Adenocarcinoma Presenting a Bizarre Urogram, Ibid., 83, 97, Scheifly, C. H., Daugherty, C. W., Greene, L. F., and Priestley, J. T. (1959): Arteriovenous Fistula of the Kidney Circulation, 19, 662.

Shetlar, M. R. (1961): Serum Glycoproteins: Their Origin and Significance, Ann. N.Y. Acad. Sci., 94, 44.

Spittel, J. A., DeWeerd, J. H., and Shick, R. M. (1959): Acute Varicocele: A Vascular Clue to Renal Tumor, Proc. Mayo Clin., 34, 134 . 
StARr, A., and Miller, G. M. (1952): Solitary Jejunal Metastasis Twenty Years After Removal of a Renal-cell Carcinoma, New Engl. Y. Med., 246, 250.

Stauffer, M. H. (1961): Nephrogenic Hepatosplenomegaly, Gastroenterology, 40, 694.

STETTER, R. (I887): Demonstration eines Extirpirten Pylorus Carcinoms und einer Extirpirten Carcinomatosen Niere, Verh. dtsch. Ges. Chir., 16, 36.

STÖRTEBECKER, T. P. (195I): Metastatic Hypernephroma of the Brain from a Neurosurgical Point of View, $\mathcal{f}$. Neurosurg., 8, 185 .

VAN VeLzER, D. A., and Lanier, R. R. (1958): A Simplified Technic for Nephrotomography, Radiology, $70,77$.

Vinson, P. P., and MARTIN, W. J. (1932): Pulmonary Metastasis from Hypernephroma Diagnosed by Bronchoscopy, Arch. Otolaryng., 15, 368.

Weinstein, E. C., Geraci, J. E., and Greene, L. F. (1961): Hypernephroma Presenting as Fever of Obscure Origin, Proc. Mayo Clin., 36, 12.

Wilson, J. R., Merrick, H., and Woodward, E. R. (196r): Hypercalcemia Simulating Hyperparathyroidism Induced by XV-2 Carcinoma of Rabbit, Ann. Surg., 154, 485.

Weyrauch, H. M., and Presti, J. C. (1956): Papanicolaou Examination of Urine in Diagnosis of Urinary Cancer; 2. False Positives in Diagnosis of Renal Neoplasms, $\boldsymbol{F}$. Urol., 75, $55 \mathrm{I}$.

Woodard, H. Q. (1953): Changes in Blood Chemistry Ass ociated with Carcinoma Metastatic to Bone, Cancer 6: 1219." ZAK, F. G. (1957): Self-healing Hypernephromas, F. Mt Sinai Hosp., 24, 1352. 